University of Nebraska - Lincoln

DigitalCommons@University of Nebraska - Lincoln

University of Nebraska Press -- Sample Books

and Chapters

University of Nebraska Press

Spring 2013

501 Baseball Books Fans Must Read before They Die

Ron Kaplan

Follow this and additional works at: https://digitalcommons.unl.edu/unpresssamples

Kaplan, Ron, "501 Baseball Books Fans Must Read before They Die" (2013). University of Nebraska Press -- Sample Books and Chapters. 166.

https://digitalcommons.unl.edu/unpresssamples/166

This Article is brought to you for free and open access by the University of Nebraska Press at DigitalCommons@University of Nebraska - Lincoln. It has been accepted for inclusion in University of Nebraska Press -- Sample Books and Chapters by an authorized administrator of DigitalCommons@University of Nebraska - Lincoln. 


\section{Baseball \\ Books Fans \\ Must Read \\ before They \\ Die}


Buy the Book 

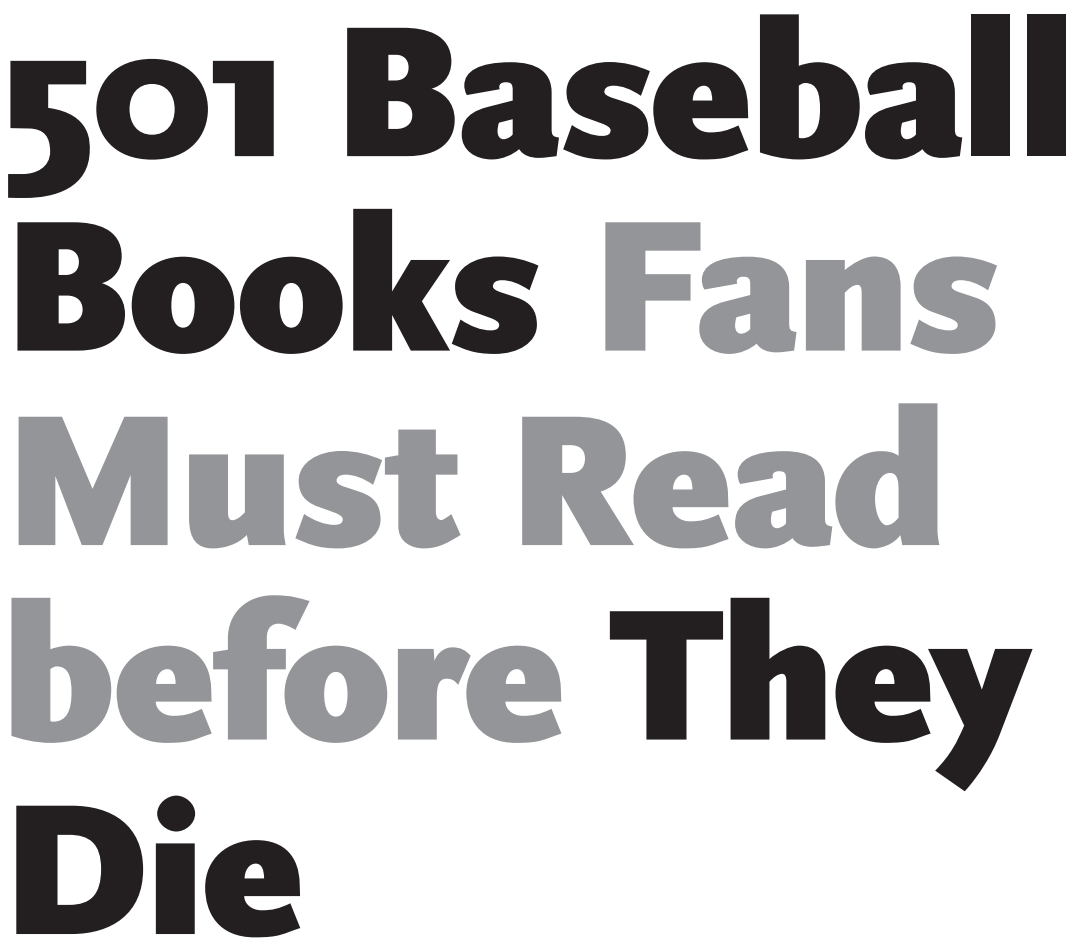

RON KAPLAN

University of Nebraska Press Lincoln \& London 
(C) 2013 by the Board of Regents of the University of Nebraska. All rights reserved. Manufactured in the United States of America. @

Library of Congress Cataloging-in-Publication Data

Kaplan, Ron, I957-

5 Or baseball books fans must read before they die / Ron Kaplan.

p. cm.

Includes bibliographical references and index.

ISBN 978-0-8032-4073-5 (pbk.: alk. paper)

I. Baseball-Collectibles-Handbooks, manuals, etc. 2. Baseball—Collectors and collecting-

Handbooks, manuals, etc. 3. Book collecting-

Handbooks, manuals, etc. I. Title.

GV875.2.K36 20I3

796.357-dc23 2012043518

Set in Scala by Laura Wellington. 
To Faith, who always believed I could do it even when I didn't believe it myself.

And to Rachel, to show that anything is possible. 
Buy the Book 


\section{Contents}

Acknowledgments ix

Introduction $\mathrm{xi}$

1. Analysis 1

2. Autobiography, Biography, and Memoir 21

3. Ballparks 101

4. Behind the Scenes 107

5. Business 115

6. Fiction 127

7. History 143

8. Instructionals 255

9. International 261

10. Minor Leagues 269

11. Pop Culture 273

12. Reference 343

13. Statistics 361

14. Umpires and Rules 369

15. For Young Readers 375

Index 383 
Buy the Book 


\section{Acknowledgments}

One of my favorite quotes comes from the memorable TV character Benjamin Franklin "Hawkeye" Pierce of $M * A * S * H$. When asked what one book he would want if stranded on a desert island, he replied, "The dictionary, because it has all the other books in it."

Along those lines, a project like this would not have been possible without all the hard work of the hundreds of authors who have written about the national pastime for the past I50-plus years. So, to paraphrase another famous character, Yogi Berra, thanks to them for making this book necessary.

Many thanks also to the fine folks at the University of Nebraska Press-Robert Taylor, Courtney Ochsner, Tish Fobben, Roger Buchholz, Tyler Holzer, Acacia Gentrup, Laura Wellington, and Rosemary Vestalfor guiding this rookie through the process. 
Buy the Book 


\section{Introduction}

In his introduction to The Norton Book of Sports, George Plimpton described his "small ball theory" of literature. Plimpton, who served as editor for the anthology, believed there was "a correlation between the standard of writing about a particular sport and the ball it utilizes - that the smaller the ball, the more formidable the literature" (I3). Accordingly, since the national pastime employs one of the smaller pieces of sporting equipment, there have been "very good books about baseball," he wrote.

Sure, it's a cliché to say that baseball is a metaphor for life (and points off for the unimaginative author who insists on including the Jacques Barzun line, "Whoever wants to know the heart and mind of America had better learn baseball," in his book), but precisely that notion is reflected in the wide range of genres from fiction to philosophy, statistics to science, and biographies to business, among others.

Perhaps it's the leisurely pace of the game, stretched out over several hours and played during the languid days of summer, that lends baseball to the printed word. The Hall of Fame Library in Cooperstown boasts a collection of more than ten thousand volumes dating back to the early nineteenth century, and the Library of Congress has similar holdings.

I make no claim that the five hundred (or so) titles you will find herein are necessarily the best baseball books; that's too subjective. But I hope they will provide an entry into the fascinating world of baseball literature, with its connections to other areas one might not 
normally associate with the game: fiction, history, science, the arts, music, and many more.

Just as there are the David McCulloughs, Stephen Kings, John Clancys, and Agatha Christies in the so-called real literary world, there are similar staples of baseball lit: W. P. Kinsella in fiction; Peter Golenbock for team and oral histories; Donald Honig for general history (with some fiction thrown in for a change of pace); Harold Seymour and David Q. Voight for their multivolume histories of the national pastime; and John Thorn, appointed as official historian for Major League Baseball in 20II, who's been a bit of a polyglot, with volumes of history, statistics, analyses, reference, and even a children's book.

The books listed here represent some of the best, most well-produced, and quirkiest examples of the various departments within the grand department store that is baseball. Of course, you might disagree. What's baseball without a good debate? If you think I left out one of your favorites or have some other bone to pick, drop me a line at RonKaplansBaseballBookshelf@gmail.com. Maybe I'll consider it for the second edition.

Some books fit into more than one category. For example, Jonah Keri's The Extra 2\%: How Wall Street Strategies Took a Major League Baseball Team from Worst to First is located in the business section of my local Barnes and Noble, rather than with the rest of the baseball titles. Similarly, a biography of necessity crosses into history, while volumes on statistics could also fit into the area of analysis. They are offered here based on the most appropriate category with additional notation of other crossover themes where appropriate.

A note on formatting: Because of their popularity, many titles have been reissued over the years, often by different publishing companies. The dates, sources, and notes herein are from editions I have either in my own library or have read elsewhere. Similarly, the identifications for the authors are based on the information given within their books at the time of publication. 


\section{Baseball \\ Books Fans \\ Must Read \\ before They \\ Die}


Buy the Book 


\section{1}

\section{Analysis}

Books in this category fall into a few subdivisions. Some will deconstruct a single game or small group of games from the point of view of a player, manager, executive, or journalist who will discuss the wherefores and whys of their philosophies. These are heavy on strategy and sometimes go into depth on the background of a particular play, piece of equipment, or other minutiae. Others will consider the same general topics, but over a greater period of time.

1. The Baseball Book, by Bill James. New York: Villard, 1992.

The Baseball Book series, published from I990-92, was, in a sense, the precursor to the Bill James Historical Baseball Abstracts. It's as though he's constantly tinkering, trying to find just the right way to express his ever-active mind. It's that curiosity that keeps him from falling into a rut and dragging his loyal readers down with him.

The format for The Baseball Books changed slightly from year to year; the I992 edition features data - both statistical and otherwise - about each team "in a box," a device James would use for each decade in his Historical Abstracts. No matter the publicationsave for those that are solely statistical in nature - he conveys the information with charm and a bit of impishness. The introduction to the I992 edition contains one word: "Hi." The foreword: "Ahem." Maybe that's a downside of being so prolific; you run out of stuff to put in your prefatory material.

The team section is followed by player rankings for each posi- 
tion and statistical category. Each year, James would include capsule biographies for players, managers, executives, and others whom the author believes had a significant impact on the game. Unfortunately, he did one letter per volume, so he only got through $C$.

Other categories: Auto/Bio/Mem, History, Pop Culture

2. The Baseball Economist: The Real Game Exposed, by J. C. Bradbury. New York: Dutton/Penguin, 2007.

The "economy" here does not just mean money, although that is the topic of several of these thought-provoking essays by Bradbury, an associate professor at Kennesaw State University and the University of the South.

He mixes things up with discussions about the game on the field and in the accounting office, as management tries to figure out what a player is worth; whether it's better for teams to take a Moneyball approach based on statistics or rely on their scouts; which is the true "golden age" of baseball and why; whether steroids really made that much of a difference; and which components of the overwhelming array of analytics provide the best information when it comes to evaluating athletes.

Books like these confound many readers who prefer not to know about such things, arguing that it detracts from their enjoyment. And, yes, Bradbury does throw around concepts like multiple-regression analysis that can make the eyes glaze over. Yet others (myself included) think you can never have too much information; it's all in the way it's presented and what the reader chooses to do with it. Like serving a new dish, it has to be palatable otherwise you lose your audience. Fortunately, Bradbury takes the time to explain his ideas into easily digestible nuggets.

Other categories: Business, History, Statistics 
3. The Baseball Fan's Companion: How to Watch a Game Like an Expert, by Nick Bakalar. New York: Macmillan, 1996.

The phrase is "play ball," not "work ball." Baseball is a game; it's supposed to be fun (although there are those curmudgeonly types who would disagree). This means that books like The Baseball Fan's Companion should not strive to be taken too seriously, and fortunately, that's exactly Bakalar's route.

He mixes his primer with bits and pieces that make no pretense of being a textbook as he delivers his lessons in almost a stream of consciousness. Bakalar follows only the loosest organization in his discussions of such items as offense, defense, pitching, and rules. (The least-enforced rule: opposing players shall not fraternize on the field while in uniform. Yeah, right.)

Of particular interest are several diagrams mapping out defensive positioning for specific situations and a too-short section on baseball chatter, in which the author offers a detailed "translation" of what a broadcaster might say and what it actually means in terms a rank beginner can follow.

Other categories: History, Pop Culture, Reference

4. The Beauty of Short Hops: How Chance and Circumstances Confound the Moneyball Approach to Baseball, by Sheldon Hirsch and Alan Hirsch. Jefferson NC: McFarland, 2011.

There are several books that propound the concepts of sabermetrics and the Moneyball approach to the game, but few titles actually come out against the theories that became so popular after the publication of Michael Lewis's book in 2003.

This father-and-son writing team takes a more old-fashioned approach. They want to show that not everything comes down to slide rules and computer printouts. That is, all the planning in the world can't foresee the little quirks of fate that make sports (and life) so interesting. Statistics, they claim, can be tweaked to support your purposes and desires. As evidence, they offer a number 
of games from 2009 that were full of bad hops, balls deflected by birds in flight, and baserunning blunders. Lewis and Billy Beane, the Oakland A's general manager on whom Moneyball is based, certainly couldn't have accounted for such circumstances in their equations.

But this is the beauty, according to the Hirsches, who write from the point of view of the fans who watch the game, as opposed to general managers with a business plan on how to put together a ball club, whether as a front-office professional or as an ersatz GM drafting a fantasy team.

Who's the audience for this book? It's certainly not a scholarly treatise, but it is a reminder of what baseball has always been and should be again, at least according to the authors: a game played by human beings, warts and all.

5. The Bill James Baseball Abstract, by Bill James. New York: Villard, 1985.

There have always been books on statistics and books of commentary, but before James came along, the two sides of the same baseball coin were rarely presented in one volume. James - who created the first of his annual Abstracts while working as a night watchman at a pork-and-beans company and sold them by mail order through advertisements in the Sporting News - used a newly developed system of "runs created" to prove who the best players really were. The first Abstracts were self-published from I977-8I, but once word about his theories and amusing presentation spread to a wider audience, James produced his work through established publishing houses from I982-88. As word about his theories and amusing presentation spread, he signed on with Ballantine Books to distribute the Abstracts throughout the I980s, after which he went on to author more diverse publications, in addition to consulting for the Boston Red Sox and other baseball outlets. Subsequent annual editions would concentrate on a specific theme - the I982 edition looked at the effects of aging on production, for example - in addition to team analysis. 
His seminal work has earned him a place in baseball lore and American pop culture: James has been profiled on 60 Minutes, and he also appeared as a guest voice on The Simpsons.

Other categories: History, Pop Culture, Statistics

6. The Book on the Book: A Landmark Inquiry into Which Strategies in the Modern Game Actually Work, by Bill Felber. New York: Thomas Dunne/St. Martin's Press, 2005.

7. The Book: Playing the Percentages in Baseball, by Tom M. Tango, Mitchel

G. Lichtman, and Andrew E. Dolphin. Dulles VA: Potomac, 2007.

"The book," as it has been traditionally regarded, is not really a physical book at all. Rather, it is a tradition, a time-honored way of doing things in a given discipline that's been accepted since time immemorial.

You'll often hear announcers say a manager is "going against the book," or, in other words, bucking long-held beliefs in an attempt to disrupt the opponent. When it works, the manager is a genius; when it doesn't, the announcers will either give him credit for trying something new or point to his faux pas as proof that the old system still works.

These two titles seek to break the mold, incorporating the everexpanding universe of sabermetrics in an attempt to discern trends that should bring about a change in the standard approach. At the same time, they both take a broad overview of the game, asking questions about the personnel makeup of a team or deciding what a player is worth, either for trade value or at the negotiating table.

Felber's Book on the Book is a direct slap at the establishment. He divides his content into the game on and off the field. In the former, he doesn't attack the old so much as he offers new ways to interpret what he believes are misconceptions. The most interesting of these chapters is his assessment of general managers. After all, while the man in the dugout has to play with the cards he's dealt, the GM is the dealer. 
Tango's The Book is an offshoot of his website (Tangotiger.net) where he, his coauthors, and their visitors discuss such matters as linear weights, base-out states, and run values. The print edition offers more than I 40 charts and tables to illustrate their points. It takes a bit of effort to get through this one but, hey, Rome wasn't built in a day.

For those of you who are not on board the sabermetric train, I can practically hear your eyes rolling at all this. I was like you once. But after reading through these essays, I can say that they can change perceptions. Even if you don't want to become an expert on that side of the equation, these books can lead you to a new appreciation for the thought processes that go into making decisions. Such tactics are becoming increasingly in vogue as a younger generation of managers and GMS who have been brought up on this data nudge the old-timers aside.

Other categories: Business, History, Statistics

\section{Bullpen Diaries: Mariano Rivera, Bronx Dreams, Pinstripe Legends, and the}

Future of the New York Yankees, by Charley Rosen. New York: HarperCollins, 2011. No dynasty lasts forever. This is especially true in the world of sports, which has a tremendous turnover rate. Sure, you can sign stud free agents and make a few key trades here and there, but the building process must come from within, and you have to give your young players a chance to develop before shipping them off to another team. Rosen, a veteran journalist and longtime Yankees fan, follows the team in an unusual fashion by concentrating solely on the production of the relief corps during each contest of the 2010 season, grading the pitchers on each game's performance from spring training though the AL Championship Series against the Texas Rangers.

Mariano Rivera, who holds the all-time record for career saves, began his Yankee career on the same minor league teams as Derek Jeter, Jorge Posada, and Andy Pettitte. Now it's time for the new regime to step in, but according to Bullpen Diaries, it will be difficult 
to find someone to fill his shoes. One quickly notices how strategy has changed over the years and how many pitchers it takes to get through a game (even more if it goes into extra innings).

Rosen's style is somewhat repetitive, but he keeps things lively with plenty of filler, including historical trivia and interviews with the pitchers and other players, as well as a roundup of what was going on in the rest of the Majors and the Minor Leagues.

He wraps up Diaries with an assessment of what the Yankees have to do to move forward, including the unenviable task of finding a replacement for their future Hall of Fame closer.

Other category: History

9. Clearing the Bases: The Greatest Baseball Debates of the Last Century, by Allen Barra. New York: Thomas Dunne, 2002.

Almost as much as watching the game on the field, hardy baseball fans love a good argument: "who's better" (both team and individual player editions) and "what if" are perennial topics of discourse.

Barra, a sports columnist who has written for the Wall Street Journal and Salon.com, among other publications, brings up several compelling points in Clearing the Bases. Some are quantifiable, while others - such as why pitchers can't throw complete games anymore, or who is the greatest living player (asked at a time when Joe DiMaggio, who insisted on being introduced with that distinction, had recently died), or why the Mets couldn't maintain their winning ways in the mid-I980s - are not.

Some might disagree with his conclusions, but then that's just part of the greater theme, isn't it?

Also by the author: Barra followed up Clearing the Bases with Brushbacks and Knockdowns: The Greatest Baseball Debates of Two Centuries (2004). Guess he remembered a few additional items, such as "Sultan of Swat vs. Splendid Splinter: If Ted is the Greatest Hitter, Why is Babe the Greatest Player?" 
10. Fair Ball: A Fan's Case for Baseball, by Bob Costas. New York:

Broadway, 2000.

After the strike of I994-95, the hot topic among baseball books was how to repair the game. Several experts - players, journalists, and broadcasters, among others - believed they had the answers to get the national pastime back on track.

Add Bob Costas to the list. His contribution is mostly a rant on the business and organization of the game. Among his suggestions is a new postseason system, even though he declared himself against a radical realignment that occasionally rears its ugly head and snaps at traditionalists. (Who knows - by the time you read this, it may have come to pass.)

Whether you love him or are put off by his almost pseudoreligious reverence for the game, you have to admit Costas has some good ideas, such as returning some postseason games to afternoon broadcasts and starting the night games at an hour that makes them actually watchable for fans on the East Coast who have to go to work or school the following morning. If Major League Baseball is serious about trying to counter flagging interest, they might want to give some of these proposals real thought. After all, this book did spend ten weeks on the New York Times best-seller list.

Other categories: Commentary, New York Times Best Seller

11. The Game: One Man, Nine Innings: A Love Affair With Baseball, by Robert Benson. New York: Penguin, 2001.

There are several books that put a single game under the microscope, examining it for various themes the author deems important. Benson takes it back a notch, looking at a Minor League contest between the Iowa Cubs and the Nashville Sounds in April 2000, a game with ostensibly even less on the line than an early season Major League affair. On the other hand, this may be the kind of game that represents the nostalgic ideal of baseball — a pleasant way to pass a warm summer's evening with family and friends. 
Benson's Game combines several perspectives: those of a writer, a father, and, of course, a baseball fan. One can imagine hanging with the author as he sits back during the course of nine innings to ruminate on myriad topics. With writing that is both spare and reverential, Benson compares the plays of the game with the ups and downs of everyday life. At one point he allows that the national pastime is a collection of the routine; few plays, he suggests, are memorable on a long-term basis.

The Game is categorized as a sports book, but it's one more in the metaphor-for-life conceit: sometimes you hit a home run, sometimes you make an error. As the game winds down, the author hopes his children will one day recall the important life lessons it offers: "I wish for them that they will remember that there will be days when the best that can be done is to move the runner ... that even the best of us ... strike out a fair amount" (I6I).

12. Inside Pitch: Life in Professional Baseball, by George Gmelch.

Washington DC: Smithsonian Institution Press, 2001.

Gmelch offers an excellent, if brief, overview of a ballplayer's life from cradle to grave, from auditioning before scouts in high school or college right up until the day he hangs up his spikes. The beauty is in its brutal honesty, so readers should beware lest their image of "the life" be shattered.

You can have all the talent in the world and still not make it to the Show due to factors outside your control, such as injury, organization indifference, or just plain bad luck. In fact, the majority of Minor Leaguers are just there so the high-priced upper-round draft picks have someone to play with. It's a sobering experience for a lot of these young men who were used to being the stars of their teams at every level. Some can't hack it; having been coddled since their tee-ball days, they're not used to hearing negatives or dealing with failure on any extended level.

But as the author points out, it's more than just the player who is involved in the hardships associated with the life. Two partic- 
ularly interesting — disturbing, even — chapters deal with wives and groupies. With Inside Pitch's 200I publication date, it seems an anachronism for Gmelch to write about wives and girlfriends as property of the players, compelled to always look their best since, obviously, these stud athletes are also judged by the company they keep. Infidelity is almost taken for granted, if not downright expected, and "clearly the baseball wife's primary goal is to support her husband and his career" (I50). The groupies are described in even more disparaging terms, described as content to get "free tickets to the game and free beer afterward" ( $\left.\mathrm{I}_{5} 5\right)$.

Gmelch, who played in the Tigers' system in the I960s, spent almost ten years working on this book. This lends him somewhat more credibility than other authors, having insider knowledge to help determine if what he's hearing from the players and others involved has the ring of truth to it.

Other categories: Behind the Scenes, History

13. It Takes More Than Balls: The Savvy Girls' Guide to Understanding and Enjoying Baseball, by Deidre Silva and Jackie Koney. New York: Skyhorse Press, 2008.

14. The Cool Chick's Guide to Baseball, by Lisa Martin. Salt Lake City: Gibbs Smith, 2003.

As a member of the male species, I have to tread carefully here. On the one hand, I think I would almost be insulted by a book that would try to explain the game based on my demographic (unless I was a child, perhaps). On the other hand, I'm all for anything that brings more fans to the baseball table.

The Cool Chick's Guide is the lighter of the two. While it does discuss the broader points of the game, such as offense, defense, and pitching, it offers a few sections that seem to appeal mostly to prefeminist women, such as "Battling the Bulge: Your Ballpark Calorie Counter" (hey, guys could stand a few tips here, too) and "Seventh Inning Stretch: It All Comes Down to Shopping." 
It Takes More Than Balls is the more serious undertaking. The reader will find much more in the way of background, history, strategy, rules, and customs, sprinkled with a generous helping of anecdotes to keep things from getting too heavy.

So, which book to read? That depends on what you want to get out of your baseball experience. Some just want a nice afternoon off, a one-shot deal with no plans to further their baseball education. For others, to borrow from Rick Blaine in Casablanca, this could be the start of a beautiful relationship; you can start with Cool Chicks and move on to More Than Balls if your interest is sufficiently piqued.

Other categories: History, Pop Culture, Women

15. Living on the Black: Two Pitchers, Two Teams, One Season to Remember, by John Feinstein. New York: Little, Brown, 2008.

Some might find five hundred pages about the thought processes of two veteran Major Leaguers a bit hard to swallow, but Feinstein has never been one to care much about public opinion. He dissected the 2007 season, in which Tom Glavine of the New York Mets was struggling to reach his three hundredth victory, while over in the Bronx, Yankee Mike Mussina was on the hunt for win number 250 - not too shabby either.

After brief recaps of their journeys from the amateur ranks through the 2007 campaign, Feinstein settles into the verbose discourse for which he has become famous. No detail is too small, no scrap of information too unimportant.

Feinstein's reputation netted him a high level of access and heretofore-unavailable insights into each ballplayer's habits, as well as the social structure of the pro sports environment, which is full of disparate personalities and quirks. The Mets, favored to win the Eastern Division that year, suffered through an epic collapse, with Glavine having perhaps his worst performance just when they needed him most. It was an ignominious end to a Hall of Fame résumé. Mussina and the Yankees, on the other hand, enjoyed a good run before losing in the postseason. 
Despite a few glitches - major or minor, depending on the reader's demand for accuracy - Feinstein's painstaking account of thoughtful craftsmen in the twilight of their careers ranks high on the list of such books.

Other categories: Auto/Bio/Mem, History

16. Men at Work: The Craft of Baseball, by George F. Will. New York: Macmillan, 1990.

The conservative political pundit and devout Cubs fan was one of the first "outsiders" to publish such an ambitious study of the game. His I990 account focuses on four distinct components, represented by Tony La Russa, then with the Oakland A's, on managing; Orel Hershiser, two years removed from a Cy Young Award, on pitching; Tony Gwynn, who led the National League in batting eight times; and "Iron Man" Cal Ripken Jr. on defense. Will was prescient in his selections: Ripken and Gwynn spent their entire careers with the Orioles and the Padres, respectively, and they were inducted into the Hall of Fame together seventeen years later.

Will presents this quartet as tops in their field, similar to the master cabinet-maker. They all took pride in their work, were wellversed in the intricacies and demands of their positions, and their "finished products" brought joy to and admiration from their customers, the fans. They provide a behind-the-scenes education on their areas of expertise that makes the reader appreciate how difficult it is to merely survive in the profession, let alone to excel for such an extended period.

Men at Work spent thirty-five weeks on the New York Times bestseller list, the most for any baseball title.

Other categories: Auto/Bio/Mem, Behind the Scenes, History, New York

Times Best Seller

Also by the author: Bunts: Curt Flood, Camden Yards, Pete Rose, and Other Reflections on Baseball (1998) 
17. Nine Sides of the Diamond: Baseball's Great Glove Men on the Fine Art of Defense, by David Falkner. New York: Times, 1990.

Turn on a sports cable channel and you're likely to see more highlights of defensive plays than home runs or pitching performances. Chicks may dig the long ball, as the Nike ad campaign claimed, but for true baseball fans it's not even close compared to an overthe-shoulder diving catch with the game on the line, as illustrated on this volume's very first page with “The Catch," Willie Mays's famous grab in the I954 World Series. A good fielding effort in a crucial spot can spiritually crush an opponent, leaving them only to ask what they have to do to catch a break.

Falkner takes the reader on a tour of the diamond, stopping at each position to discuss the qualities it takes to be a top-notch practitioner of that particular piece of real estate. He focuses on three to five of the best at each in an effort to see what they have in common with each other and what separates them from everyone else. It's not just superior athleticism; you need brains as well. You need to know exactly how to position yourself according to each situation, including the batter, the pitcher, the score, and the runners on base.

Few books on defense capture all these nuances as well as Nine Sides of the Diamond.

Other category: Behind the Scenes

Also by the author: The Short Season: The Hard Work and High Times of Baseball in the Spring (1986); Sadaharu Oh: A Zen Way of Baseball (collaborator, 1984); The Last Hero: The Life of Mickey Mantle (1995)

18. Pure Baseball: Pitch by Pitch for the Advanced Fan, by Keith Hernandez and Mike Bryan. New York: HarperCollins, 1994.

Show of hands: How many out there get a bit miffed by the formerjock broadcast analyst who basically does nothing but carp about poor execution and profess that things were better when he was still playing?

That's certainly the feeling I get these days, but prior to joining the Mets' broadcast booth, former Mvp and five-time All-Star 
Keith Hernandez collaborated with Mike Bryan for this astute and informative breakdown that is never condescending, despite the "advanced fan" snob appeal of the title.

Hernandez analyzes two games to explain why the ballplayers and managers do what they do when they do it. It reminds me of a high school science project, only a lot more fun; it never feels like a dry lecture. Hernandez supplements the play-by-play with anecdotes based on his own experiences and observations, giving the book an almost folksy appeal.

Other category: History

Also by the author: If At First: A Season with the Mets (with Mike Bryan,

I986); Shea Goodbye: The Untold Inside Story of the Historic 2008 Season

(with Matthew Silverman, 2009)

19. The Scouting Report: 1995 , edited by Gary Gillette. New York: Harper Perennial, 1995.

This unique series gave fans an insight previously unavailable: the opportunity to see the strengths and weaknesses of every active player just as their opponents discussed them in pregame meetings.

The first edition, published in I983, featured commentary from a combination of former ballplayers and broadcasters, people in a good position to offer educated opinions, including Jerry Coleman, Ernie Harwell, Ralph Kiner, Tim McCarver, Ned Martin, and Brooks Robinson (although how much actual writing and scouting they did is a matter of conjecture). The Scouting Reports were published under several stewardships, including stats Inc. and the Baseball Workshop.

By I995 the process was considerably smoother and more aesthetically appealing. Each regular player had a full page. Pitchers were scrutinized for their general ability and command of their repertoire, as well as their fielding and ability to hold base runners. Charts compared a particular player to other pitchers in his league for several key categories.

Similarly, batters were judged on their general approach to hit- 
ting, base running, and fielding. Their graphs considered batting average, on-base percentage, runs and home runs, and R B Is per five hundred at bats. There were also "spray charts" indicating how and where they hit against righties and lefties.

One of several publications produced annually during the late I980 and early I990s that looked to cash in on the popularity of the Bill James Baseball Abstracts, The Scouting Report also featured a few of each organization's top prospects and others to watch, albeit to a lesser degree than the full-timers.

20. Spalding Answers to Baseball's Most Asked Questions, by A. Lou Vickery. Indianapolis IN: Masters Press, 1995.

The slim volume packs quite a punch, as it takes on quite a large responsibility.

From the simplest (What are the formulas for the standard statistics?) to the more difficult (Why is there an infield fly rule anyway?), Vickery, a former Minor Leaguer and coach, provides the answers in a manner that is neither patronizing to fans who already have a good knowledge nor too technical for newbies.

Categories in this volume include the finer points of batting, pitching, fielding, baserunning, and signs, as well as managerial strategy, umpires and rules, and records. There's also a separate glossary for quick reference.

And just to prove that baseball is still a game and not to be taken too seriously, Vickery thoughtfully concludes with a chapter on how baseball terminology has become a staple in everyday language and a transcript of Abbot and Costello's famous "Who's on First" routine.

Other categories: History, Pop Culture 
21. A Thinking Man's Guide to Baseball, by Leonard Koppett. New York:

Dutton, 1967.

A veteran sportswriter and columnist for several New York City newspapers, Koppett wrote one of the earliest (and still best, in my opinion) overviews of the wherefores and whys of baseball, mixing serious analysis with a gentle sense of humor.

Without the benefit of the Internet or modern analytics, Koppett - who received the J. G. Taylor Spink Award from the Baseball Hall of Fame in I992 - scrutinized the game, from offense to defense, business to broadcasting, and the Minor Leagues to marketing, to name only a few. This is not so much a history of baseball, which Koppett also wrote about in his usual pleasant manner, as it is a friendly conversation. You never get the feeling he's showing off, being in with the in crowd, or dropping names.

Koppett's Guide went through several revisions, including the most recent (and more politically correct in its title) The Thinking Fan's Guide to Baseball, published posthumously in 2004. Naturally, it includes topics that weren't on the radar when the original went to press, such as the designated hitter, free agency, and the increasing power of the Players Association.

In an article for TheColumnists.com published shortly after Koppett's death in 2003, his longtime friend and colleague, Maury Allen, described the first edition of the original Guide as "an intellectual look at the simple game."

Other categories: Classic, History

Also by the author: Koppett's Concise History of Major League Baseball (1998, revised in 2004); The Man in the Dugout: Baseball's Top Managers and How They Got That Way (1993); The New York Mets (1974) 
22. This Time Let's Not Eat the Bones: Bill James Without the Numbers, by Bill James. New York: Villard, 1989.

For this anthology, James selected what he believed were the most informative and entertaining of his previous writings. Most of the pieces were extracted from his popular annual Abstracts, while other pieces appeared in Esquire magazine.

Some of the pieces are quite extensive, while others, such as this selection from the I987 edition of the Abstract, are as brief as one line: “The Montreal Expos of Gary Carter's last years were a team with more holes than a porcupine's underwear" (47).

The comments are divided into five categories: teams; players; people (mostly managers and owners); essays (including a lengthy piece on James's love for the teams in his hometown of Kansas City); and research, in which the author revisits some of his favorite topics covered in previous Abstracts, the more unusual the better. All carry James's informative, offbeat, and thought-provoking style.

That's the great thing about James's work: having started out selfpublishing, he doesn't give a hang for being commercial or popular. He writes what he wants and that's just fine with his fans.

Other categories: History, Statistics

23. Three Nights in August: Strategy, Heartbreak, and Joy Inside the Mind of a Manager, by Buzz Bissinger. Boston: Houghton Mifflin, 2005.

In this volume, Bissinger offers an in-depth examination of the national pastime, and he expands on the familiar theme of focusing on a game and microanalyzing what goes through a manager's mind.

In this case, the author chose a three-game series between Dusty Baker's Chicago Cubs and Tony La Russa's Saint Louis Cardinals in 2003. La Russa, who retired after the 20II season and is a potential Hall of Fame candidate, won five pennants and two World Series titles between the Oakland A's and the Cards, so he was obviously an appropriate candidate for such a study.

Imagine watching a game with the ability to pause the action so 
the color commentator can provide an in-depth backstory on every player and event, then pressing the play button to resume the action. While that might get old after a while, a good portion of the audience would appreciate being privy to such inside dope.

Three Nights in August spent twenty weeks on The New York Times best-seller list.

Other categories: History, New York Times Best Seller

\section{Tim McCarver's Baseball for Brain Surgeons and Other Fans:}

Understanding and Interpreting the Game So You Can Watch It Like a Pro, by Tim McCarver with Danny Peary. New York: Villard, 1998.

Baseball for Brain Surgeons offers plenty of examples and anecdotes drawn from nearly a half century of McCarver's experiences - a twenty-year playing career followed by many more seasons in the broadcast booth for the New York Mets and, later, for Fox Sports.

McCarver's book delves deeper into strategy and nuance than most introductions. It's an excellent source to gain understanding in all facets of the game: how a pitcher or, more frequently, a manager decides what to throw; what goes through a hitter's mind as he steps into the batter's box with the game on the line; how an outfielder positions himself according to who's on base; or how a speedy runner uses his savvy to know when not to steal.

Those who prefer watching the game from the comfort of their living rooms will cultivate a new appreciation for television broadcasts, as McCarver explains how the director pulls the action together, what he or she looks for, and what is not seen on the screen. Of course, media technology has advanced a bit since the book came out more than a decade ago, but the basics are still the same. 
25. Watching Baseball Smarter: A Professional Fan's Guide for Beginners, Semi-Experts, and Deeply Serious Geeks, by Zack Hample. New York:

Vintage, 2007.

For a long time I posted a weekly listing of Amazon.com's best-selling baseball titles. It was a fool's errand, since the rankings were updated hourly, so by the time I finished gathering the information and making the entry, it could have changed a couple of times.

But one book that was a staple of the lists (along with Moneyball), was this humble little book by Hample, a thirtysomething überfan whose claim to fame is his collection of more than five thousand baseballs caught at Major League ballparks.

Watching Baseball Smarter is one of the most fan-friendly books of its kind. Hample discusses the basics for newcomers (which is a boon to old-timers as well, who might have a lingering question or two despite their considerable knowledge) — fundamentals for each position, basic statistics, stadiums, umpires, and "random stuff to know" - before wrapping it up with a glossary of baseball slang.

Other categories: Classic, Pop Culture

Also by the author: How to Snag Major League Baseballs: More Than 100 Tested Tips That Really Work (1999); The Baseball: Stunts, Scandals, and Secrets Beneath the Stitches (20II)

26. Why Is the Foul Pole Fair? Or, Answers to the Baseball Questions Your Dad Hoped You Wouldn't Ask, by Vince Staten. New York: Simon and Schuster, 2003.

Dad hopes you don't ask because he might not know the answers, but Staten, who frequently writes about life's "did you ever wonder" moments, has done a terrific job of resolving those gnawing queries about the whys of the game.

Strictly speaking, this isn't a Q\&A book. Rather, it's the author's detailed examination of a 2002 game between the Cincinnati Reds and the Florida Marlins at what was then known as Cinergy Field. 
With his young son, Will, in tow, Staten addresses the entire ballpark experience, from hot dog vendors to umpires to the scoreboard (and the players and play, of course, although that almost seems secondary to the narrative), from the ridiculous to the sublime. For example, I had no idea a turnstile costs about $\$ 2,600$ and allows 750 patrons to pass through per hour; I feel so enlightened now.

Even the most casual observation opens the door to an in-depth description of the history of groundskeeping or the inner workings of the public address system. Some other topics Staten contemplates include tobacco, radar guns, the press box, preparing the baseballs for the game, headgear, Cracker Jack, the seventh-inning stretch, and scorecards, all of which make for fascinating reading for anyone who is not content with just watching the players.

Other categories: Auto/Bio/Mem, Behind the Scenes, Trivia Also by the author: Ol' Diz: A Biography of Dizzy Dean (I992) 